\title{
Article
}

\section{The Therapeutic Relationship in China: A Systematic Review and Meta-Analysis}

\author{
Ying Mao ${ }^{1,2, *}$, Wei Ning ${ }^{1,2}$, Ning Zhang ${ }^{1,2}$, Tao Xie ${ }^{1,2}$, Jinnan Liu ${ }^{1,2}$, Yongbo Lu ${ }^{1,2}$ and Bin Zhu ${ }^{3}$ \\ 1 School of Public Policy and Administration, Xi'an Jiaotong University, Xi'an 710049, China; \\ ningwei@stu.xjtu.edu.cn (W.N.); ningzhang.xjtu@foxmail.com (N.Z.); xietao2014077049@stu.xjtu.edu.cn (T.X.); \\ kennanliu@stu.xjtu.edu.cn (J.L.); whl1692881375@stu.xjtu.edu.cn (Y.L.) \\ 2 Research Center for the Belt and Road Health Policy and Health Technology Assessment, \\ Xi'an Jiaotong University, Xi'an 710049, China \\ 3 School of Public Health and Emergency Management, Southern University of Science and Technology, \\ Shenzhen 518055, China; binzhu2-c@my.cityu.edu.hk \\ * Correspondence: mao_ying@mail.xjtu.edu.cn
}

Citation: Mao, Y.; Ning, W.; Zhang, N.; Xie, T.; Liu, J.; Lu, Y.; Zhu, B. The Therapeutic Relationship in China: A Systematic Review and Meta-Analysis. Int. J. Environ. Res. Public Health 2021, 18, 3460. https:// doi.org/10.3390/ijerph18073460

Academic Editor: Paul Tchounwou

Received: 23 February 2021

Accepted: 22 March 2021

Published: 26 March 2021

Publisher's Note: MDPI stays neutral with regard to jurisdictional claims in published maps and institutional affiliations.

Copyright: (c) 2021 by the authors. Licensee MDPI, Basel, Switzerland. This article is an open access article distributed under the terms and conditions of the Creative Commons Attribution (CC BY) license (https:// creativecommons.org/licenses/by/ $4.0 /)$.
Abstract: With a surge of conflicts between healthcare workers and patients in recent years, the therapeutic relationship (TR) in China is presently in tension. Meanwhile, consequent issues have begun to emerge, such as the distrust between healthcare workers and patients and the decline in the quality of medical services. Although many empirical studies about the TR have been conducted in China, previous studies on TR and its influencing factors have been contradictory. Therefore, this study conducted a systematic review and meta-analysis to assess the current situation of the TR and to identify factors associated with the TR in Chinese hospitals from three perspectives (healthcare worker, patient, and therapeutic interaction). Two reviewers independently searched the literature, selected researches, and extracted data through comprehensively searching of three international electronic databases and three Chinese electronic databases to identify all relevant observational studies on influencing factors for TR in China published in English and Chinese from January 2000 to January 2020. Among the 3290 records initially identified, 11 studies met the selection criteria. A total of 96,906 individuals were included in the review. The results showed that $55.73 \%$ of healthcare workers consider the TR to be tense, and $33.7 \%$ of patients hold this view. The meta-analysis indicated that healthcare workers who were male, older, less educated, working in a non-surgical department, and had a senior title were more likely to be pessimistic about the TR. Patients who were rural residents, highly educated, and had no medical insurance were more likely to be pessimistic about the TR. Furthermore, the mutual trust could improve rapport between healthcare workers and patients. The 25 other related factors related to the TR were analyzed and described using a narrative approach. The findings might deserve consideration in the design of relative policies to promote harmony between doctors and patients.

Keywords: therapeutic relationship; medical disputes; determinants; systematic review; meta-analysis

\section{Introduction}

In China, contradictions between doctors and patients have dramatically increased nationwide in recent years. Patients sometimes use harmful behaviors against doctors, resulting in bad consequences, which has aroused the attention of the medical industry and various groups in China. Coordinated and harmonious therapeutic relationship (TR) is an important factor to improve the quality of medical treatment. However, the TR is quite tense in the Chinese context [1-3], and patients' satisfaction with medical treatment and healthcare worker-patient trust is damaged [4,5]. Also, healthcare workers do not earn deserved respect, verbal attacks, emotional conflicts, injuries and even killings happen from time to time. Moreover, disharmonies and contradictions of TR will disrupt patients' 
adherence to treatment and continuity of medical care $[3,6]$, and further affecting the quality of health services. As a result, people's sense of well-being and health has severely been affected.

Medical disputes, the primary but not the only symbol of the deteriorating doctorpatient relationship, have become increasingly prominent in recent years, impacting the development and optimizing of TR. Previous studies have reported that medical professionals are more vulnerable to workplace violence than other professionals $[7,8]$. In the United States, the number of medical disputes more than tripled from 1991 to 2005 [9]. A survey of workplace violence between nurses and patients in the United States showed that $76 \%$ of nurses had been attacked by patients or patient family members [10]. In 2017, 288 physical injuries and approximately 2600 psychological insults occurred in Germany, and nearly $40 \%$ of doctors experienced physical conflicts [11]. This rapid growth of medical disputes existed not only in Western countries but also in Asia. For example, in Japan, it was reported that the number of medical malpractice lawsuits had increased ten times from 102 in 1960 to 1019 in 2003 [12].

In the Chinese context, people have been largely dependent on the public services provided by the government since ancient times [13,14], and their demand for health services is no exception. Public hospitals funded by the government have always occupied a dominant position in the medical industry [15]. However, since the reform of China's economic system in 1993, excessive marketization prompted the ambitions of medical personnel chasing interests [16,17], as well as led to the majority of patients flocking to tertiary hospitals. Therefore, the so-called "difficult and expensive to get medical treatment" problem has been developed throughout China $[1,18,19]$. The public benefit of public hospitals has gradually weakened, and the bitterness and contradictions between doctors and patients have deepened. Additionally, the institutionalized communication and mediation mechanism of public hospitals in China are generally not sound [1]. After medical disputes occur, patients lack channels to express their appeals, which contributes to the intensification of contradictions between healthcare workers and patients in China, and even the frequent occurrence of violent injuries to healthcare workers. A survey conducted by the Chinese Medical Doctor Association in 2017 reported that $66 \%$ of medical personnel had experienced verbal abuse or physical injury [20]. Moreover, the public ordinarily tends to be partial to the weak, and people show more sympathy and compassion to patients in medical disputes [17]. People generally show more empathy to patients' situations before they fully understand what happened. With the various social grievances inevitably aggravated by the problem of "difficult and expensive to get medical treatment" in China, as well as the one-sided reports by the media [21], healthcare workers and patients, become two parties with opposing interests rather than a "community of interests."

The TR also has strong sociocultural attributes in essence. Under the joint action of social transformation and healthcare system reform, the conflict and contradiction between doctors and patients were no longer the individual conflict between doctors and patients, but have risen gradually to a wide range of group areas and social problems [22]. On the one hand, in China's current model of healthcare, the progress of modern medical science and technology has increased the medical staff's dependence on medical equipment, resulting in that the therapeutic interaction has been seriously materialized. The integrity of people has been replaced by organs, tissues, cells, and genes, while the humanistic and psychological interaction between doctors and patients is relatively lacking. A national survey found that the average inquisition time for patients in tertiary hospitals was only $11.5 \mathrm{~min}$ in 2019, which is far less than the average waiting time for patients (24.1 $\mathrm{min}$ ) [23]. The doctors tend to be concerned more with the disease in a biomedical sense, rather than the whole patient as a person [24]. Therefore, there are model-based differences [25] between China and countries implementing the person-centered care (PPC) that a model emphasizes that medical services should not only pay attention to the treatment of patients diseases, but also pay more attention to the patients' living conditions, psychological needs, emotional feelings, and other mental states at a higher level. On the other hand, the high degree of medical information asymmetry and distrust of the medical process 
(caused by social cognition) result in that there are differences or even conflicts between doctors and patients on the spiritual interests such as status in power or right, human dignity, pursuit of equality, and realization of personal value. As a result, doctors are in the dominant side of the game spontaneously in the therapeutic interaction process, such as information advantage and position advantage. A research report, issued jointly by the World Bank (WB), the World Health Organization (WHO), and the authorities of the Chinese government, put forward to set the "People-Centered and Integrated Health Care" (PCIC) for the next stage of China's healthcare system reform key strategy [26]. However, the implementation of the PCIC in China is still in its initial stage, and the Chinese healthcare setting is still widely affected by the old biomedical model.

Furthermore, this "contradiction pattern" may trigger a vicious cycle [27] in that poor TR would undermine the mutual trust between healthcare workers and patients, which would, in turn, result in medical disputes. Therefore, it is important to analyze the determinants of the TR and to establish effective strategies to improve such relationships. Previous studies have explored the effects of various factors on the TR, such as healthcare worker-related factors (i.e., age [28-34], gender [34-40], years of experience [41,42], education level [43-45], ethnicity [45], marital status [44], professional title [46,47], department $[28,48,49]$, income $[45,50,51]$, income satisfaction $[45,52,53]$, etc.,), patient-related factors (i.e., age [44,45,51], gender [44,45,51], residence [54-56], ethnicity [45], education level [57,58], medical insurance [47,59], medical expense [59], household income [45], waiting time [45], etc.,), and other factors (i.e., doctor-patient trust [60,61], doctor-patient communication [62,63], etc.,). Obviously, previous studies have been conducted to investigate the individual factors and socioeconomic factors for both doctors and patients, as well as factors related to the therapeutic interaction.

Although many empirical studies have been conducted in China, most were published in Chinese journals, and no systematic reviews related to the TR have been found. Therefore, this study aimed to conduct a systematic review and meta-analysis to assess the current situation of the TR and its determinants (from three perspectives of healthcare worker, patient and healthcare-patient interaction) and to identify factors associated with the TR in Chinese hospitals.

\section{Materials and Methods}

According to the Preferred Reporting Items for Systematic Reviews and Meta-Analyses guidelines we following (Known as PRISMA, Ottawa Hospital Research Institute) [64], this study comprehensively searched published studies that investigated the determinants of the TR in electronic databases. This systematic review was conducted based on English and Chinese databases from 1 January 2000 to 1 January 2020. We searched the following English databases: PubMed, EMBASE and Web of Science; we also searched the following Chinese databases: China National Knowledge Internet Database (CNKI), Wanfang Database, and China Biology Medicine disc (CBM/Sinomed).

\subsection{Search Strategy}

The same keywords were used for each database search for China "[(China) OR (Chinese)]," therapeutic relationship "[(doctor-patient relationship) OR (clinician-patient relationship) OR (therapist-patient relationship) OR (physician-patient relationship) OR (doctor-patient relation) OR (clinician-patient relation) OR (therapist-patient relation) OR (physician-patient relation) OR (the relationship between doctor and patient) OR (the relationship between physician and patient) OR (the relation between doctor and patient) OR (the relation between physician and patient) OR (the relation between clinician and patient) OR (the interactions between doctor and patient) OR (the interactions between clinician and patient) OR (the interactions between physician and patient) OR (medical dispute) OR (conflict between doctor and patient) OR (conflict between physician and patient) OR (conflict between clinician and patient) OR (medical trouble)]," and determinant 
"[(determinant) OR (factors) OR (influences)]". The specific search strategy is shown in the Supplementary File.

\subsection{Eligibility Criteria}

According to the objective of this study, the characteristics of selection criteria were determined through discussions, which were summarized in Table 1 . The eligibility criteria were as follows: (1) studies (without language restrictions) that were published in a peerreviewed journal from 1 January 2000 to 1 January 2020 and located in China were included. (2) Studies in which participants included doctors, nurses (excluding doctors or nurses in internship and medical students), and patients were included. (3) Studies that analyzed the current situation of the TR and its related factors affecting the TR were included. (4) Studies with original data were included. (5) Only cross-sectional studies were included.

Table 1. Characteristics of selection criteria.

\begin{tabular}{|c|c|}
\hline Characteristics & Criteria \\
\hline Study type & Empirical studies published in a peer-reviewed journal \\
\hline Study design & Cross-sectional studies \\
\hline P (Population) & Doctors/Nurses and Patients \\
\hline I (Intervention) & Population with positive attitudes towards the TR \\
\hline $\mathrm{C}$ (Comparator) & Population with pessimistic attitudes towards the TR \\
\hline O (Outcomes) & $\begin{array}{l}\text { Studies that analysed the current situation and the } \\
\text { related determinants, factors or influences of TR }\end{array}$ \\
\hline Language & None language restrictions \\
\hline Publication period & After 1 January 2000 and before 1 January 2020 \\
\hline
\end{tabular}

\subsection{Data Extraction and Quality Assessment}

Two independent reviewers (Wei Ning and Ning Zhang) participated in the data extraction by screening the acquired studies at the same time, according to the flow diagram. All discrepancies were resolved through discussions, leading to full group consensus. All articles were extracted into an extraction form focused on identifying the following for each study: the first author, year of publication, locations, participants, sample size, qualified rate, analytical perspective, determinants, negative cases, rate of negative cases, and the number of references.

According to the Grading of Recommendations: Assessment, Development, and Evaluation (GRADE) approach [65], a modified Newcastle-Ottawa scale (NOS) was utilized to assess the quality of the included studies. The quality assessment criteria consisted of seven components: (1) representativeness of the sample, (2) sample size, (3) non-respondent rate, (4) ascertainment of the exposure, (5) comparability of subjects in different outcome groups, (6) assessment of the outcome, and (7) use of an appropriate statistical test. The total quality assessment score of each study was 7, which was divided into three levels: good quality (score of 5-7), medium quality (score of 3-4), and poor quality (score of 1-2). Studies with medium and good quality were included in our analysis.

\subsection{Statistical Analysis}

We used RevMan 5.3 (The Cochrane Collaboration, Oxford, UK) and Stata 16.0 (Stata Corp, College Station, TX, USA) to statistically analyze the results from the included studies. This study mainly analyzed the determinants of the TR from the perspectives of healthcare workers, patients, and therapeutic interactions. All related variables extracted from the included articles were added to the standard extraction form, and the different variables were transformed into binary variables to permit dichotomous meta-analysis. However, only the same variables or variables that could be combined into the same types were included in the meta-analysis. The variable screening process is shown in the Supplementary File. 
The determinants included in the meta-analysis were those reported in at least three articles. For the meta-analysis, we conducted a dichotomous meta-analysis and computed the summary risk estimate by using a fixed-effect model. The significance of the pooled odds ratio (OR) was determined by the Z-test, with $p<0.05$ considered statistically significant. The $\mathrm{Q}$ statistic was calculated to estimate the heterogeneity, and $p \leq 0.10$ was considered statistically significant [66]. We assessed the possibility of publication bias for the studies included in the meta-analyses with Egger's linear regression test, which was used to quantitatively evaluate the publication asymmetry, and a $p<0.05$ was set as statistically significant.

If it was infeasible to make a quantitative synthesis and conduct a meta-analysis for a variable, studies that reported the same determinants were grouped, and a narrative approach and descriptive statistics were used to compare their associations with the TR.

\section{Result}

\subsection{Search Results}

As shown in Figure 1, 3290 articles were initially identified after conducting the search strategy, and 2118 articles remained after directly removing duplicate literature. After reviewing the title or abstract, 1957 articles that did not meet the eligibility criteria were discarded. Among the remaining 161 studies, 150 articles were removed after full-text review for the following reasons: (1) 46 articles were not cross-sectional studies, (2) 71 articles had no original data, (3) 31 articles lacked standard sampling, and (4) 2 articles were literature reviews. Ultimately, 11 studies were included.

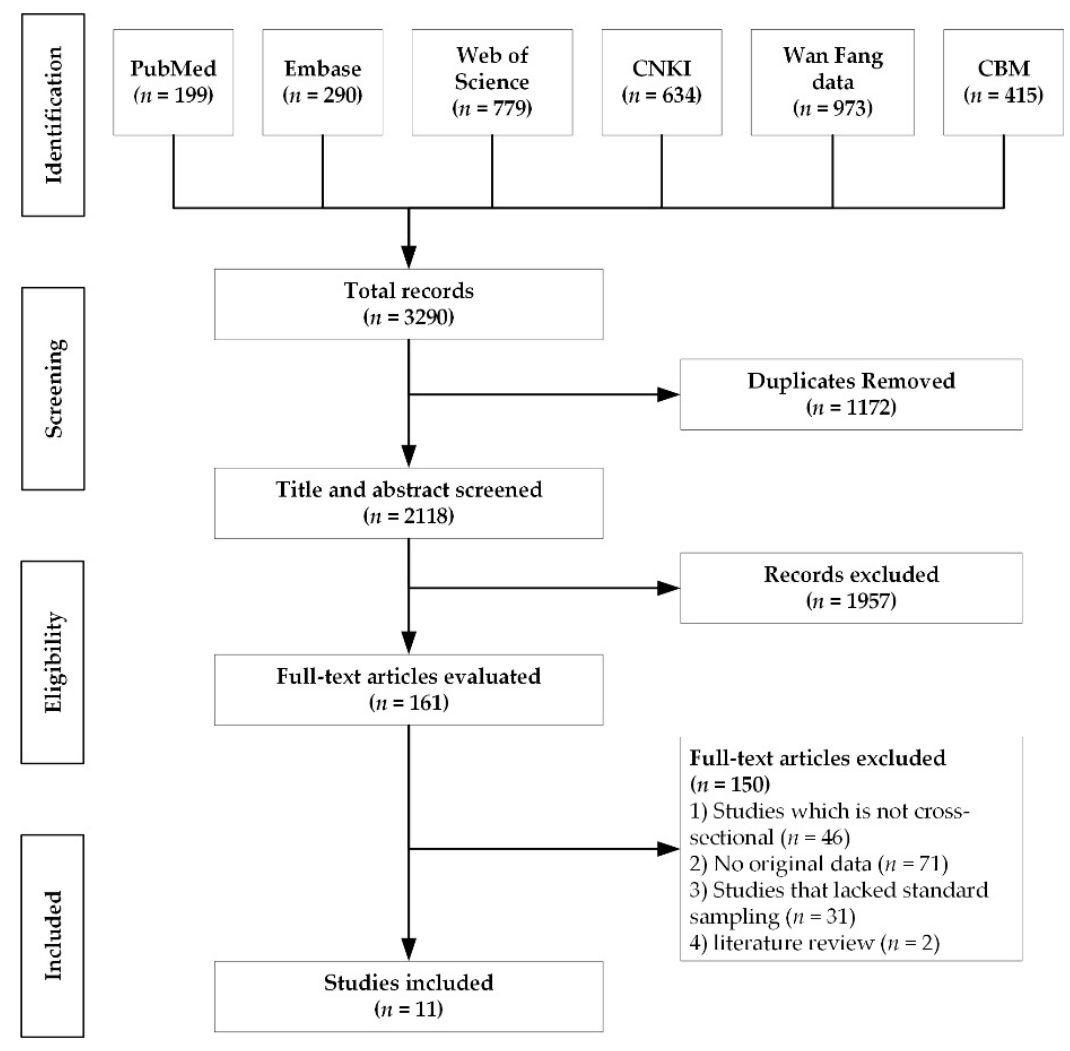

Figure 1. Flow diagram of study selection.

\subsection{Analysis of the Included Articles}

The characteristics of the included articles are presented in Table 2 . A total of 11 articles contained 65,006 healthcare workers and 31,900 patients distributed throughout China. Of the 11 articles, 4 articles analyzed the determinants only from the healthcare worker perspective (HWP) [67-70], 2 articles analyzed the determinants from only the patient 
perspective (PP) [71,72], 1 article analyzed the determinants from both the HWP and the therapeutic interaction perspective (TIP) [73], 2 articles analyzed the determinants from both the PP and the TIP [74,75], 1 article analyzed the determinants from both the HWP and the PP [76], and 1 article analyzed the determinants from the HWP, PP, and TIP [77].

Table 2. Characteristics of 11 included studies.

\begin{tabular}{|c|c|c|c|c|c|c|}
\hline Authors & Location & Participants & $\begin{array}{c}\text { Sample Size } \\
\text { (Effective Response } \\
\text { Rate \%) }\end{array}$ & $\begin{array}{l}\text { Analytical } \\
\text { Perspective }\end{array}$ & Determinants & $\begin{array}{l}\text { Negative } \\
\text { Cases Rate *, } \\
\text { N (\%) }\end{array}$ \\
\hline Shi, 2017 [67] & $\begin{array}{l}16 \text { provinces * } \\
\text { (municipalities or } \\
\text { autonomous } \\
\text { regions) }\end{array}$ & Nurses & $15,970(74.77)$ & HWP & $\begin{array}{l}\text { Gender, Age, Education level, Marital } \\
\text { status, Professional title, Employment } \\
\text { form, Income, Department, Years of } \\
\text { experience, Working time per day, Time } \\
\text { spent in direct contact with patients. }\end{array}$ & $10,502(65.76)$ \\
\hline Zhao, 2017 [73] & Chongqing & $\begin{array}{l}\text { Medical } \\
\text { personnel }\end{array}$ & 520 (not stated) & HWP \& TIP & $\begin{array}{l}\text { HWP: Education level, Professional title, } \\
\text { Income satisfaction, Medical ethics, } \\
\text { Workload, Whether disputed with } \\
\text { patient, Whether medical disputes } \\
\text { interfere with work. } \\
\text { TIP: Healthcare worker-patient trust. }\end{array}$ & $421(80.96)$ \\
\hline Yuan, 2017 [68] & Shanxi & $\begin{array}{l}\text { Medical } \\
\text { personnel }\end{array}$ & $3663(81.40)$ & HWP & $\begin{array}{l}\text { Gender, Age, Years of experience, } \\
\text { Education level, Professional title, } \\
\text { Marital status, Employment form, } \\
\text { Department, Income. }\end{array}$ & $2334(63.72)$ \\
\hline Liu, 2018 [69] & Nationwide & $\begin{array}{l}\text { Medical } \\
\text { personnel }\end{array}$ & 44,086 (not stated) & HWP & $\begin{array}{l}\text { Gender, Age, Hospital type, Region, } \\
\text { Professional title, Administrative } \\
\text { position, Department, Income, Medical } \\
\text { liability insurance. }\end{array}$ & $24,540(55.66)$ \\
\hline Gao, 2015 [70] & Chongqing & Doctors & $160(100)$ & HWP & $\begin{array}{l}\text { Education level, Professional title, } \\
\text { Workload, Daily average rate of } \\
\text { outpatient visits, Working time per day, } \\
\text { Whether disputed with patient, Whether } \\
\text { worry about encountering dispute. }\end{array}$ & $132(82.50)$ \\
\hline Zhao, 2018 [71] & Nationwide & Outpatients & 29,105 (99.82) & PP & $\begin{array}{l}\text { Hospital type, Region, Age, Gender, } \\
\text { Department, Whether first visit, } \\
\text { Education level, Medical insurance, } \\
\text { Household income, Registration, } \\
\text { Registered residence, Sources of patients, } \\
\text { Whether have a familiar doctor, Whether } \\
\text { have family doctors, Referral. }\end{array}$ & $8752(30.07)$ \\
\hline Zhang, 2011 [74] & Weifang & Patients & 498 (not stated) & PP \& TIP & $\begin{array}{l}\text { PP: Medical expenses, Whether have } \\
\text { family doctors. } \\
\text { TIP: Service attitude, Service quality and } \\
\text { level, Treatment effect, Whether } \\
\text { healthcare worker receives kickbacks on } \\
\text { medications or medical devices, } \\
\text { Doctor-patient trust, Whether adequate } \\
\text { medical information is shared, Whether } \\
\text { patient bribes or entertains doctors *. }\end{array}$ & $234(46.99)$ \\
\hline Wang, 2015 [77] & Wuhan & $\begin{array}{l}\text { Patients \& } \\
\text { Medical } \\
\text { personnel }\end{array}$ & $\begin{array}{l}\text { Medical personnel: } \\
618 \text { (not stated) } \\
\text { Patients: } \\
618 \text { (not stated) }\end{array}$ & $\begin{array}{l}\text { HWP \& PP } \\
\text { \& TIP }\end{array}$ & $\begin{array}{l}\text { HWP: Gender, Age, Years of experience, } \\
\text { Education level, Professional title, Career } \\
\text { satisfaction, ability to handle dispute. } \\
\text { PP: Gender, Registered residence, Age, } \\
\text { Education level, Occupation, Medical } \\
\text { insurance, operation, Medical expenses. } \\
\text { TIP: Service attitude. }\end{array}$ & $\begin{array}{l}\text { Medical } \\
\text { personnel: } \\
\text { 206 (33.33) } \\
\text { Patients: } \\
206 \text { (33.33) }\end{array}$ \\
\hline Yang, 2014 [75] & Hubei & Patients & $1539(95.60)$ & PP \& TIP & $\begin{array}{l}\text { PP: Age, Education level, } \\
\text { Medical insurance. } \\
\text { TIP: Healthcare worker-patient } \\
\text { communication, Healthcare } \\
\text { worker-patient trust. }\end{array}$ & 203 (13.19) \\
\hline Deng, 2010 [76] & Changsha & $\begin{array}{l}\text { Patients \& } \\
\text { Medical } \\
\text { personnel }\end{array}$ & $\begin{array}{c}\text { Medical } \\
\text { personnel: } 49 \\
\text { Patients: } 140 \\
\text { (Total qualified rate: } \\
\text { 99.47) }\end{array}$ & HWP \& PP & $\begin{array}{l}\text { HWP: Age, Gender, Professional title, } \\
\text { Department, Education level. } \\
\text { PP: Age, Gender, Education level, } \\
\text { Registered residence, Medical insurance, } \\
\text { Household income. }\end{array}$ & $\begin{array}{l}\text { Medical } \\
\text { personnel: } \\
4(8.16) \\
\text { Patients: } \\
80(57.10) \\
\end{array}$ \\
\hline Liu, 2010 [72] & Urumqi & Patients & 1514 (not stated) & PP & Medical insurance, Education level & $303(20.01)$ \\
\hline
\end{tabular}

* 16 provinces (municipalities or autonomous regions) mean Beijing, Tianjin, Hebei, Shandong, Guangdong, Liaoning, Shanxi, Henan, Anhui, Hunan, Heilongjiang, Ningxia, Shannxi, Gansu, Sichuan, and Chongqing. *'negative cases' means the population with pessimistic attitudes towards the TR. * 'patient entertains doctors' means that patients invite the doctors to dinner in order to get an appointment with a better doctor, better care, or some preferential treatments else. 
Fifty determinants were extracted from the included studies and were categorized into three groups: (1) 24 healthcare worker-related factors: gender, age, years of experience, education level, professional title, department, hospital type, region, income, income satisfaction, working time per day, marital status, employment form, administrative position, whether disputed with patient, workload, medical ethics, whether medical disputes interfere with work, career satisfaction, ability to handle dispute, whether worry about encountering dispute, daily average rate of outpatient visits, medical liability insurance, and time spent in direct contact with the patient; (2) 18 patient-related factors: gender, age, registered residence, education level, occupation, medical insurance, medical expenses, household income, whether have a familiar doctor, hospital type, region, department, whether first visit, registration, sources of patients, whether have family doctors, referral, and operation; (3) 8 therapeutic interaction-related factors: healthcare worker-patient trust, service attitude, service quality and level, treatment effect, whether healthcare worker receives kickbacks on medications or medical devices, whether adequate medical information is shared, healthcare worker-patient communication, and whether patient bribes or entertains doctors.

\subsection{Quality of the Included Articles}

The quality score of 11 articles ranged from 5 to 7 (shown in Table 3), and the average score was 6 out of 7 according to the modified Newcastle-Ottawa scale. All studies were of good quality. Five articles did not meet the sample representative standard (sample size $\geq 1000$ ). Five articles did not report the non-respondent rate. All studies met other assessment criteria.

Table 3. Assessment of risk of bias.

\begin{tabular}{|c|c|c|c|c|c|c|c|c|}
\hline Authors & $\begin{array}{l}\text { Sample Repre- } \\
\text { sentativeness }\end{array}$ & $\begin{array}{l}\text { Sample } \\
\text { Size }\end{array}$ & $\begin{array}{c}\text { Respondent } \\
\text { Rate }\end{array}$ & $\begin{array}{l}\text { Ascertainment } \\
\text { of the Exposure }\end{array}$ & $\begin{array}{l}\text { Comparability of } \\
\text { Subjects in Different } \\
\text { Outcome Groups }\end{array}$ & $\begin{array}{c}\text { Outcome } \\
\text { Assessment }\end{array}$ & $\begin{array}{l}\text { Appropriate } \\
\text { Statistical Test }\end{array}$ & Total Score \\
\hline Shi, 2017 & 1 & 1 & 1 & 1 & 1 & 1 & 1 & 7 \\
\hline Zhao, 2017 & 0 & 1 & 0 & 1 & 1 & 1 & 1 & 5 \\
\hline Yuan, 2017 & 1 & 1 & 1 & 1 & 1 & 1 & 1 & 7 \\
\hline Liu, 2018 & 1 & 1 & 0 & 1 & 1 & 1 & 1 & 6 \\
\hline Gao, 2015 & 0 & 1 & 1 & 1 & 1 & 1 & 1 & 6 \\
\hline Zhao, 2018 & 1 & 1 & 1 & 1 & 1 & 1 & 1 & 7 \\
\hline Zhang, 2011 & 0 & 1 & 0 & 1 & 1 & 1 & 1 & 5 \\
\hline Wang, 2015 & 0 & 1 & 0 & 1 & 1 & 1 & 1 & 5 \\
\hline Yang, 2014 & 1 & 1 & 1 & 1 & 1 & 1 & 1 & 7 \\
\hline Deng, 2010 & 0 & 1 & 1 & 1 & 1 & 1 & 1 & 6 \\
\hline Liu, 2010 & 1 & 1 & 0 & 1 & 1 & 1 & 0 & 5 \\
\hline
\end{tabular}

Notes: Study type: cross-sectional; sore: $1=$ achieved, $0=$ not achieved.

\subsection{Analysis of Healthcare Worker-Related Factors}

Of the 11 included articles, a total of 7 analyzed the healthcare worker-related factors. Based on these 7 studies, the incidence of healthcare workers with pessimistic attitudes toward the TR ranged from $8.16 \%$ to $82.50 \%$, as shown in Table 2. Overall, the mean proportion of negative attitudes was $55.73 \%$ (SE: $10.10 \%$, 95\% CI: $31.02-80.43 \%$ ).

Among all extracted healthcare worker-related factors, six factors were included in the meta-analysis, and all the extracted determinants were included in the descriptive analysis. Figure 2 shows the meta-analysis results of the healthcare worker-related factors. Gender (male vs. female, OR: $1.48,95 \%$ CI: $1.42-1.55, p<0.00001$ ), age ( $\leq 50$ years old vs. $>50$ years old, OR: $0.86,95 \%$ CI: $0.80-0.93, p<0.0001$ ), education level (undergraduate or below vs. master or above, OR: $1.39,95 \%$ CI: $1.21-1.60, p<0.00001$ ), department (surgery vs. other, OR: $0.92,95 \%$ CI: $0.88-0.96, p<0.0001$ ), and professional title (intermediate or below vs. senior, OR: $0.77,95 \%$ CI: $0.74-0.81, p<0.00001$ ) were significantly associated with TR. However, years of experience $(p=0.21)$ was not significantly associated with the TR. The results indicated that male healthcare workers, those over 50 years old, those with a bachelor's degree or less, those in non-surgical departments and those with senior professional titles were more likely to be pessimistic about the TR. 


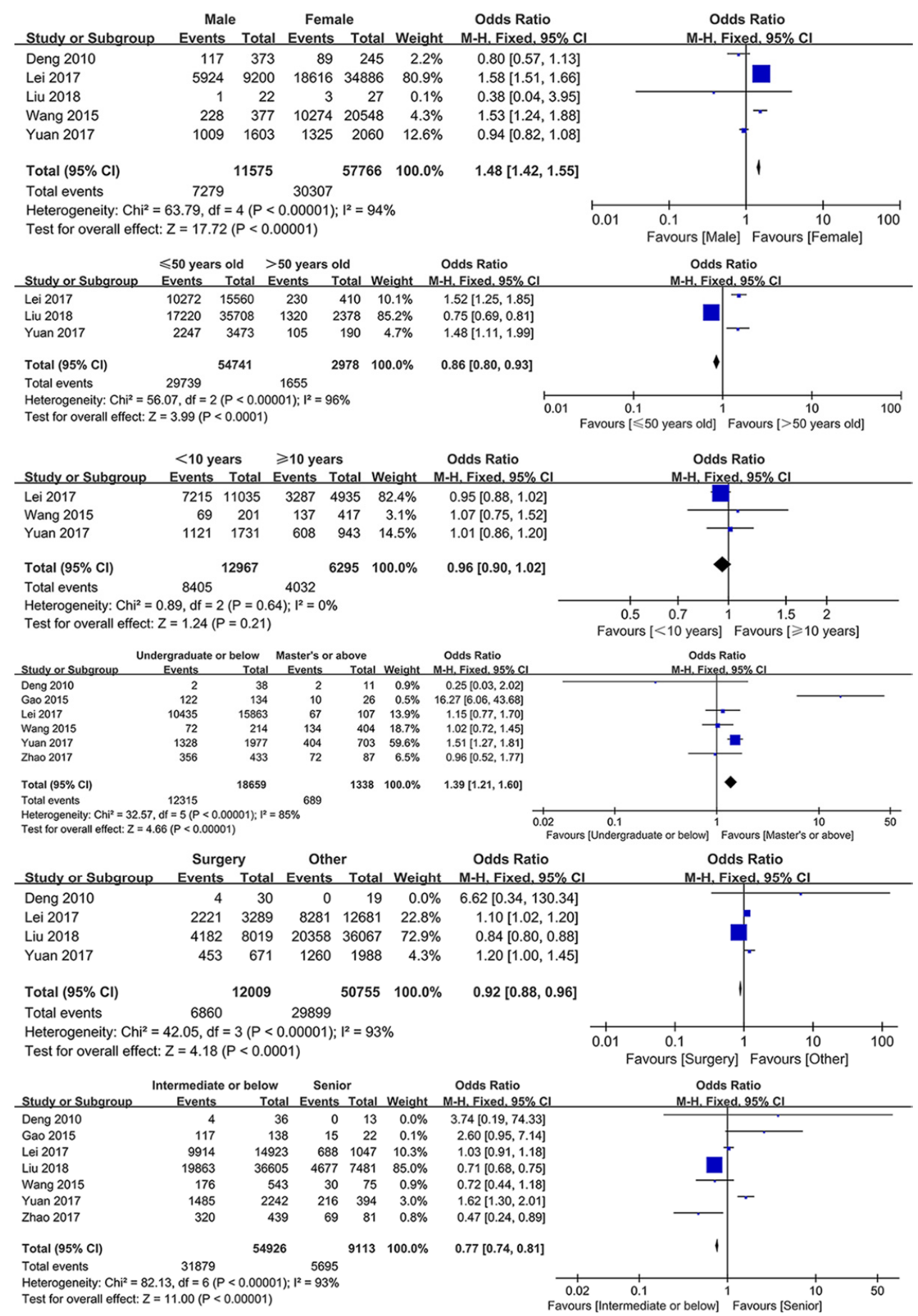

Figure 2. Forest plots of healthcare worker-related determinants.

Among other healthcare worker-related factors reported in these 7 studies, the determinants that were significantly associated with the TR included working time per day, workload, income satisfaction, medical ethics, whether medical disputes interfere with work, whether worry about encountering disputes, daily average rate of outpatient visits, hospital type, administrative position, medical liability insurance, and time spent in direct contact with patients. The occurrence of pessimistic attitudes and medical disputes was more likely for healthcare workers who had longer working times $[67,70]$, had greater working pressure [70,73], were less satisfied with income [73], had worse medical ethics [73], had more daily outpatients [70], worked in comprehensive hospitals rather than specialty hospitals [69], had no administrative position [69], had no medical liability insurance [69], 
and spent longer time in contact with patients [67]. Meanwhile, the more likely the healthcare workers are to be affected by medical disputes, the more pessimistic their perception of the TR is [73].

\subsection{Analysis of Patient-Related Factors}

Of the 11 included articles, a total of 6 analyzed patient-related factors. Based on the 6 studies, the incidence of patients with pessimistic attitudes toward the TR ranged from $13.19 \%$ to $57.10 \%$, as shown in Table 2 . Overall, the mean proportion of negative attitudes was $33.45 \%$ (SE: $6.70 \%$, 95\% CI: $16.24-50.66 \%$ ).

Among all extracted patient-related factors, five determinants were included in the meta-analysis, and all the extracted determinants were included in the descriptive analysis. Figure 3 shows the meta-analysis results of patient-related factors. Registered residence (urban vs. rural, OR: 0.92, 95\% CI: 0.87-0.97, $p<0.001$ ), education level (below undergraduate vs. undergraduate or above, OR: $0.75,95 \%$ CI: $0.72-079, p<0.00001)$, and lack of medical insurance (medical insurance vs. no medical insurance, OR: 0.77, 95\% CI: 0.67-0.89, $p=0.0004)$ were significantly associated with TR. However, gender $(p=0.11)$ and age $(p=0.96)$ were not significantly associated with the TR. The results indicated that rural patients, patients with a bachelor's degree or above, and uninsured patients were more likely to be pessimistic about the TR.

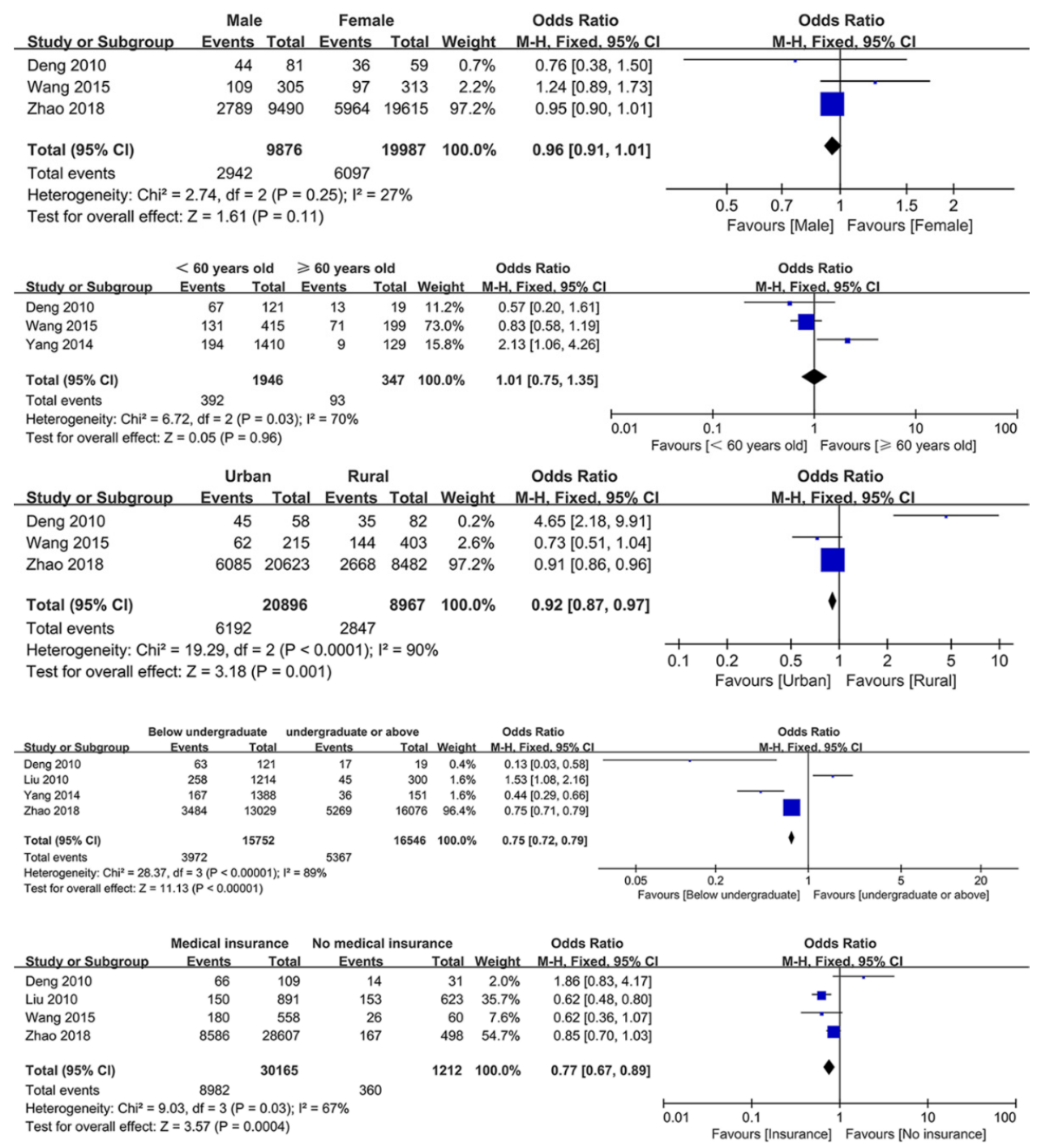

Figure 3. Forest plots of patient-related determinants. 
Among other patient-related factors reported in these 6 studies, the determinants that were significantly associated with the TR included occupation, medical expenses, household income, whether they had a familiar doctor, type of visiting hospital, region, department, and whether they were at their first visit, and whether they had family doctors. The occurrence of pessimistic attitudes or medical disputes was more likely to occur in patients who had no regular occupation [77], had higher medical expenses [74,77], had no familiar doctors or family doctors [71,74], were not at their first visit [71], visited a specialty hospital [71], visited the department of gynecology or pediatrics [71], and resided in the western region of China [71].

\subsection{Analysis of Therapeutic Interaction-Related Factors}

Of the 11 included articles, a total of 4 analyzed the therapeutic interaction-related factors. Among all extracted therapeutic interaction-related factors, one determinant was included in the meta-analysis, whereas all the extracted determinants were included in the descriptive analysis. Figure 4 shows the meta-analysis results of therapeutic interaction-related factors. Healthcare worker-patient trust (trust vs. distrust, OR: 0.24, 95\% CI: $0.18-0.32, p<0.00001$ ) was significantly associated with TR. The results indicated that cultivating trust between healthcare workers and patients can reduce the conflicts between them.

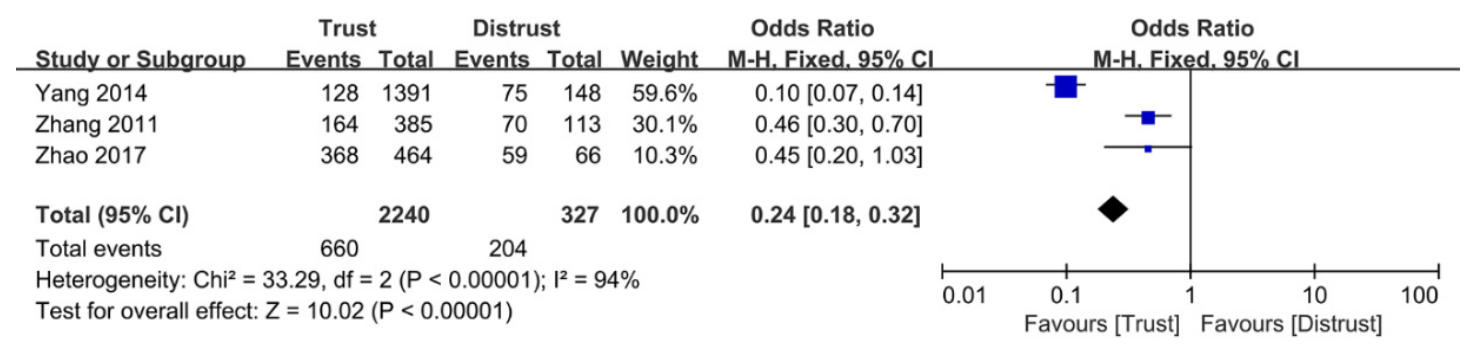

Figure 4. The forest plot of healthcare worker-patient trust.

Among other therapeutic interaction-related factors reported in 4 studies, the determinants that were significantly associated with the TR included service attitude, service quality and level, treatment effect, whether healthcare worker receives kickbacks on medications or medical devices, whether adequate medical information is shared, healthcare worker-patient communication, and whether patient bribes or entertains doctors. These 3 of 4 studies reported that if there are good service attitudes [74,77], high service quality and level [74], good treatment effects [74], sufficient medical information sharing [74], and effective communication [75] in the doctor-patient interaction, the TR will tend to be harmonious. However, if the healthcare workers receive kickbacks on medications or medical devices, or the patients bribe or entertain the doctor during the treatment [74], the TR will become tense.

\section{Discussion}

In this study, we conducted a systematic review of the present situation and related determinants of the TR in China. Seven articles reported the present situation of the TR from the perspective of healthcare workers, whereas six articles reported the present situation of the TR from the perspective of patients.

The synthesis of the data of 11 articles confirmed that there were significant differences in the evaluation of the TR situation between healthcare workers and patients [35]. The proportion of healthcare workers with pessimistic attitudes toward the TR ranged from $8.16 \%$ to $82.50 \%$ (mean: $55.73 \%$, SE: $10.10 \%$, $95 \%$ CI: $31.02-80.43 \%$ ). However, the proportion of patients with pessimistic attitudes toward the TR ranged from $13.19 \%$ to $57.10 \%$ (mean: $33.45 \%$, SE: $6.70 \%$, 95\% CI: $16.24-50.66 \%$ ). The $95 \%$ confidence intervals of two groups are overlapped, which cannot definitively support that the proportion of healthcare workers who held that the TR with a relatively tense situation was higher than 
that of patients. However, plenty of previous studies testified this finding [35,52,78,79]. This finding was considered to be the result of the poor practice environment and the high sensitivity to disputes of healthcare workers $[80,81]$, which was thought to be related to the fact that most patients are inclined to rely on and trust healthcare workers when seeking medical help [35]. Medical activities account for a large proportion in the life of healthcare workers. For example, the opportunity and time for healthcare workers to participate in healthcare workers-patient interactions are often much higher than that of patients. In addition, healthcare workers in China, especially those in tertiary hospitals, are under a bad practice environment such as heavy workload and working pressure [82], heavy pressure from public opinion [79], and social prejudice [83]. Therefore, healthcare workers have more pressure to maintain the TR than patients, and they are highly sensitive to medical disputes and have a sense of self-protection. In Nigeria, a study showed that the doctorpatient relationship was the most important practice orientation for doctors [39]. Taking defensive medicine for instance [84], in order to avoid lawsuits for misdiagnosis, healthcare workers often perform multiple medical checkups (though some are found unnecessary after a patient's disease is diagnosed). Obviously, defensive medicine is an important response behavior of healthcare workers with high sensitivity to medical disputes. However, defensive medicine is also one of the reasons for the increase in medical costs in recent years [84], further exacerbating the problem of "expensive to get medical treatment" in China. In the long run, defensive medicine is bound to do more harm than good to the TR. As for the patients, they generally trust and have faith in healthcare workers as a group [85]. Moreover, patients demanding quality care are becoming commonplace [86,87]. The slow pace of the reformation of China's healthcare system is strong evidence of this phenomenon. In order to alleviate the working pressure of tertiary hospitals, as well as the problem of "difficulty in getting medical treatment," the Health Ministry of China has been committed to diverting patients' choice of medical treatment through the implementation of a tiered diagnosis and treatment model since 2015. However, due to the lack of supporting policies and the low quality of primary medical services [88], it is still unable to effectively guide patients with mild illness to seek medical treatment in community hospitals or secondary hospitals. The situation is the opposite of that in the UK in that National Health Service has a strict system of referrals. Except for emergencies, British citizens with general health problems are the first to go to a general practitioner. Most problems can be solved successfully, even if there are a few difficult problems that require a referral to the hospital [89]. Although few studies have been done in other countries on cognitive differences of the TR between healthcare workers and patients, such differences do exist in other countries [90]. For example, a study from Canada reported that due to information asymmetry, differences in the professional division of labor, knowledge background, and differences in rights and interests between healthcare workers and patients, both sides have significantly different cognitions and attitudes toward TR [91]. This study also analyzed the related determinants of the TR. A total of 50 determinants were identified, of which 36 were determined to have significant associations with the TR, including 16 healthcare worker-related factors, 12 patient-related factors, and 8 therapeutic interaction-related factors.

\subsection{Impact of Healthcare Worker-Related Factors}

In terms of healthcare worker-related factors, first, male healthcare workers were more likely to hold a pessimistic attitude toward the TR than female healthcare workers were. However, many previous studies in China reported that there was no gender difference $[30,67,68,77]$. Conversely, studies in other countries reported the same conclusion as our study [34,36,38-40]. Previous studies argued that female doctors had advantages over men in many aspects of medical treatment. For example, female doctors are more patient-oriented [37] and more sensitive to relationship values [92]. Patients generally preferred female doctors because they deemed that the characteristics of female doctors were more in line with the characteristics of "good doctors." An investigation found that $63 \%$ of female doctors felt their relationship with their patients was friendly rather than 
business-like, compared with only $42 \%$ of male doctors [38]. Second, we concluded that healthcare workers over 50 years old were more likely to hold pessimistic attitudes toward TR. In contrast, this finding is inconsistent with the existing evidence from previous studies, which showed that doctors had high risks of holding pessimistic attitudes toward TR were those who were younger (lower age) [28-33]. Moreover, Yun X, et al. and Tianjiao M, et al. reported that healthcare workers over 50 years old had a better appraisal of the TR. In Nigeria, doctors aged 30 years and above had significantly higher mean scores on doctorpatient relationships than their colleagues [39]. Third, healthcare workers with a master's degree or above had a better perception of the TR, partly because healthcare workers with an advanced degree received more empathy and medical humanities education. Although China's medical humanities education is weak in general [93], previous study has shown that the higher the grade of medical students, the more medical humanities education they receive, and the better their ability of humanistic care [94]. Whereas plenty of studies have proved that empathy and medical humanistic education have a positive effect on TR [95-98]. A study in the United States also considered that a better education background reflected, to a certain extent, excellent medical skills and flexible communication skills in healthcare workers [43]. Meanwhile, education played a buffering role in avoiding medical disputes as communication skills, doctor-patient relationships and other issues are covered in higher education [43]. Some previous studies reported the same results [68,70]. Fourth, the relationship with patients is more harmonious for surgical healthcare workers than for other departments' healthcare workers. A previous study found that the proportion of surgeons who believed that the TR was increasingly harmonious was significantly higher than that of practitioners of internal medicine, obstetrics, gynecology, etc., [28]. Meanwhile, some studies concluded that healthcare workers in emergency departments were more likely to experience medical disputes than healthcare workers in other departments $[48,49,67,68]$. On the one hand, the patients in the emergency department and their family members are more anxious and have higher expectations for the healthcare workers [99]; on the other hand, the healthcare workers in the emergency department have a heavy workload [99]. Thus, it is particularly crucial to cultivate empathy between doctors and patients in the emergency department. Fifth, senior professional titles had a significant association with a high risk of medical disputes. A previous study reported that compared with intermediate and junior doctors, senior doctors had a stronger sense of tension toward the TR [46]. Although these senior doctors had rich experience in communication with patients, their workload and work pressure affected the doctor-patient relationship. In addition to the above factors, substantial previous studies have suggested that doctors with high income-satisfaction could maintain a harmonious relationship with patients [45,52,53,73]. In Germany, America, and Italy, a better healthcare workers-patient relationship was correlated with higher job satisfaction [100-102], which was confirmed by many previous studies [29,103-107]. In studies from the United States and Hong Kong, a heavy workload was shown to worsen the quality of communication and medical service, which in turn easily triggered medical disputes $[50,108]$. In Iran and the United States, a better doctor-patient relationship was inseparable from the enhancement of medical ethics [54,55].

\subsection{Impact of Patient-Related Factors}

In terms of patient-related factors, first, rural patients were more likely to hold a pessimistic attitude toward the TR than urban patients, which was consistent with the conclusions of previous studies in China [41,71,76]. As the majority of urban patients had more income than rural patients, their medical burden was relatively lighter, which partly eased the tensions. Nevertheless, a study from Germany suggested that urban patients showed poorer doctor-patient relationships than rural patients [56]. Second, patients with a better educational background tended to hold a worse perception of TR. This conclusion was similar to that of studies in China [30,41,71] and other countries [57,58]. Patients with low educational levels are highly dependent on and have high trust in doctors $[30,57]$. In contrast, patients with better educational backgrounds had higher 
expectations and requirements of doctors in all aspects, which partly raised the bar for patient satisfaction. Finally, medical insurance, medical expense, and household income had significant associations with TR. High medical expenses would place a substantial economic burden on patients with low household incomes, which could increase their dissatisfaction with healthcare workers when defensive medical behavior occurs. Adequate evidence has shown that patients with medical insurance tend to have a better relationship with healthcare workers than do patients who pay out of pocket [41,71,72,76]. Moreover, the reimbursement rate and range of medical insurance coverage may also affect the TR [109]. Therefore, the establishment of a sound medical insurance system, to a certain extent, would ease patient burdens and improve the TR [47,59].

\subsection{Impact of Therapeutic Interaction-Related Factors}

In terms of therapeutic interaction-related factors, first, a higher prevalence of medical disputes was found among the therapeutic relationships with a low degree of trust. Mutual trust between healthcare workers and patients could construct a favorable atmosphere for the TR. Substantial previous studies from Norway [60], Singapore [110], America [61], the Netherlands [111], Australia [112], and China [47,109] argued that trust played a crucial role in fostering a win-win TR. Second, effective communication could promote rapport between healthcare workers and patients. This viewpoint is consistent with abundant previous studies $[62,63,113-115]$. The important components of effective communication should include patient-centered communication $[60,116]$ and adequate medical information sharing $[59,117]$. Therefore, this study supports the idea that healthcare workers occupy the dominant position in healthcare worker-patient communication, which suggests that training in communication skills for healthcare workers should be strengthened [118,119]. Third, service attitude $[39,81]$ and medical quality $[39,120]$ had significant associations with TR. Evidence from a previous study showed that patients not only paid attention to the quality of their medical results (medical effects) but also took the quality of the service process seriously [121]. Meanwhile, service attitude is also an important factor in the assessment of service process quality. Therefore, more attention to doctors' behavior and attitudes is needed in the process of standardizing medical services. Finally, the existence of medical rebates and rent-seeking behavior negatively impact TR [46,52,74,122-124].

\subsection{Study Strengths and Limitations}

To our knowledge, this is the first systematic review to analyze the determinants related to the TR in China. Our findings present an overview of the current evidence from Mainland China. One strength of this review was that the analysis of the TR in China was based on a large sample size of 11 articles and 96,906 individuals (65,006 healthcare workers and 31,900 patients). Another strength was the comprehensive analyses of the determinants, particularly the meta-analysis and narrative analysis. Fifty determinants were extracted from the 11 included studies. Sixteen healthcare worker-related factors, twelve patient-related factors, and eight therapeutic interaction-related factors were significantly associated with the TR. However, three limitations existed in this systematic review. First, significant heterogeneity among the individual studies was found when performing the meta-analyses, which limited the ability to synthesize evidence clearly. Second, articles presenting results from other health professionals such as pharmacists and technicians have not been obtained. Most empirical studies on TR in China are conducted from the perspectives of doctors and nurses, while few studies on TR among healthcare workers in other professions, among which no relevant studies met the selection criteria. Furthermore, articles using the Patient-Doctor Relationship Questionnaire (PDRQ) and the Difficult Doctor-Patient Relationship Questionnaire (DDPRQ) measurement tools were not included in this study, resulting in that the current situation of the TR in China could not be measured systematically. To address these limitations, more studies should be included by changing the search strategy. Furthermore, additional studies that explore the influences of health policy-related determinants on the TR in the Chinese context are necessary. It would 
also be meaningful to further review qualitative studies on the TR to add depth and help explain some of the reported findings.

\section{Conclusions}

With a screened sample including 65,006 healthcare workers and 31,900 patients, this systematic review and meta-analysis highlight the attitudes toward TR and the heterogeneity among different groups of people. More than half $(55.73 \%)$ of healthcare workers and more than one-third of patients $(33.70 \%)$ believe their relationship is tensed at present. The percentages are significantly higher among those of male, old, less educated, and senior-titled health workers and rural, well-educated, and also those disadvantaged non-insured patients. The findings might deserve consideration in the design of relative policies to ensure harmony between doctors and patients. There is no doubt that strengthening mutual communication and therapeutic relationship strategies based on person-centered care (PCC) is the key to improving the relationship from the perspective of health professionals. Given the current situation of heavy workload in tertiary hospitals in China [125], the government may want to pay more attention to the burnout of health workers in tertiary hospitals.

Supplementary Materials: The following are available online at https:/ /www.mdpi.com/article/10 $.3390 /$ ijerph18073460/s1, Supplementary File: The search strategy, extracted factors, the distribution of factors and the extracted data.

Author Contributions: Y.M. and W.N., conceived this research project. W.N. and N.Z., developed the search strategy, collected the data, designed and executed the analyses, interpreted the findings, wrote the first draft, revised subsequent drafts, and prepared the manuscript. T.X., J.L., Y.L., B.Z., and W.N., revised the drafts of the manuscript. All authors have read and agreed to the published version of the manuscript.

Funding: The Major Project of National Social Science Fund of China: Research on big health putting prevention first and construction of healthy China (grant number 17ZDA079).

Institutional Review Board Statement: Not applicable.

Informed Consent Statement: Not applicable.

Data Availability Statement: No new data were created or analyzed in this study. Data sharing is not applicable to this article.

Acknowledgments: The authors would like to thank the National Office for Philosophy and Social Sciences of China for their supports.

Conflicts of Interest: The authors declare no conflict of interest.

$\begin{array}{ll}\text { Abbreviations } \\ \text { TR } & \text { Therapeutic Relationship } \\ \text { PCC } & \text { Person-Centered Care } \\ \text { WB } & \text { The World Bank } \\ \text { WHO } & \text { The World Health Organization } \\ \text { PCIC } & \text { People-Centered and Integrated Health Care } \\ \text { PRISMA } & \text { Preferred Reporting Items for Systematic Reviews and Meta-Analyses } \\ \text { CNKI } & \text { China National Knowledge Internet Database } \\ \text { CBM } & \text { China Biology Medicine disc } \\ \text { GRADE } & \text { The Grading of Recommendations: Assessment, Development, and Evaluation } \\ \text { HWP } & \text { Healthcare worker Perspective } \\ \text { PP } & \text { Patient Perspective } \\ \text { TIP } & \text { Therapeutic Interaction Perspective } \\ \text { OR } & \text { Odds Ratio } \\ \text { PDRQ } & \text { Patient-Doctor Relationship Questionnaire } \\ \text { DDPRQ } & \text { Difficult Doctor-Patient Relationship Questionnaire }\end{array}$




\section{References}

1. Wang, L.Q. An analysis on the governance of medical disputes and conflicts in china during the social transformation period. Mod. Hosp. 2020, 20, 1753-1756.

2. $\mathrm{Hu}, \mathrm{N}$. Research on the Current Situation, Causes and Countermeasures of Doctor-Patient Disputes in the New Era. China Health Stand. Manag. 2020, 11, 20-23.

3. Xu, Z.W.; Pan, K.L.; Ye, X.X. Analysis of Causes and Policy Recommendations of Disharmony between Doctors and Patients. Hosp. Manag. Forum 2020, 37, 38-41.

4. Mao, Y.; Xie, T.; Ning, W. The Influence of Medical Service Quality on Patients' perception of Doctor-Patient Relationship: Mediating Effect Analysis Based on Patient satisfaction. J. Xi'an Jiaotong Univ. (Soc. Sci.) 2020, 40, 119-127.

5. Shi, Z.; Liu, J. Fracturing and bridging: Cognitive differences in doctor-patient relationship and improvement of doctor-patient trust: A case study in Inner Mongolia. Mod. Commun. 2019, 23, 92-93.

6. Kim, S.S.; Cho, D.Y.; Park, B.K.; Hwang, I.K.; Chang, C.L.; Lee, Y.M.; Yune, S.J. Differences in Patients' Awareness of Doctors' Communication Styles, Patients' Satisfaction, and Patients' Compliance among Patient Social Styles. Korean J. Med. Educ. 2008, 20, 321-331. [CrossRef]

7. Alkorashy, H.A.; Al, M.F. Workplace violence against nursing staff in a Saudi university hospital. Int. Nurs. Rev. 2016, 63, 226-232. [CrossRef]

8. Fallahi-Khoshknab, M.; Oskouie, F.; Ghazanfari, N.; Najafi, F.; Tamizi, Z.; Afshani, S.; Azadi, G.; Student, M. The Frequency, Contributing and Preventive Factors of Harassment towards Health Professionals in Iran. Int. J. Community Nurs. Midwifery 2015, $3,156$.

9. Jena, A.B.; Seabury, S.; Lakdawalla, D.; Chandra, A. Malpractice risk according to physician specialty. N. Engl. J. Med. 2011, 365, 629-636. [CrossRef] [PubMed]

10. Speroni, K.G.; Fitch, T.; Dawson, E.; Dugan, L.; Atherton, M. Incidence and cost of nurse workplace violence perpetrated by hospital patients or patient visitors. J. Emerg. Nurs. 2014, 40, 218-228, 295. [CrossRef] [PubMed]

11. China Minutes: German 'Medical Dispute': Nearly 40 Percent of Doctors Have Been Beaten. 2018. Available online: http: //www.oushinet.com/europe/germany/20180510/290943.html (accessed on 15 February 2020).

12. Hiyama, T.; Yoshihara, M.; Tanaka, S.; Chayama, K. Trend in Japanese malpractice litigation involving gastrointestinal endoscopy. Am. J. Gastroenterol. 2009, 104, 251-252. [CrossRef]

13. Guan Tian, G.S. Don't rely on government protection for everything. Fancy Grass (Class. Read.) 2015, 5, 16.

14. Qian, J. Overdependence on the Government to be Guarded against in Improving the People's Wellbeing. J. Guizhou Univ. Financ. Econ. 2012, 1, 1-5.

15. Wang, X.Y.; Lei, X.S. The impact of the rapid development of private hospitals on public hospitals and the countermeasures of public hospitals. J. Med. Theory Pract. 2016, 29, 1826-1828.

16. Song, S.S.; Wang, F.Y. Study on the Causes and Improvement Paths of Disharmonious Doctor-patient Relationship. Mod. Hosp. Manag. 2020, 18, 89-92.

17. Chen, D.H. Ethical Diagnosis and Treatment of the Tense Relationship between Doctors and Patients: Rationality and Limitation. J. Jiangsu Univ. (Soc. Sci. Ed.) 2020, 22, 52-63.

18. Zhao, H.L.; Zhong, M. About the predicament and policy improvement of "difficult and expensive to get the medical treatment" in our country. Rural Econ. Sci. Technol. 2019, 30, 149-150.

19. Ma, S.X.; Li, K.Z.; Zheng, F.Y.; Li, S.N. Discussion on Harmonious Doctor-patient Relationship in the New Era and Under the New Contradictions. Heilongjiang Med. J. 2019, 43, 294-296.

20. Chinese Medical Doctor Association. White Paper on the Practice of Doctors in China. Chinese Medical Doctor Association. 2017. Available online: http:/ / www.cmda.net/u/cms/www/201807/06181247ffex.pdf (accessed on 15 February 2020).

21. Zhao, K.D.; Zhang, W.; Yi, Y.X.; Chen, Y.R.; Cao, J. Exploration on the Reform of Humanistic Quality Education for Medical Students from the Perspective of Improving Doctor-Patient Relationship. J. Jinzhou Med. Univ. (Soc. Sci. Ed.) 2020, 18, 28-30.

22. Li, Z.X.; Zhang, J.; Zhu, L.Y.; Yin, H.Y.; Liu, G.D.; Ji, C.Y.; Huang, X.H.; Hang, L.; Yu, J.F. Time Attribute of China's Doctor-patient Conflict and Social Governance Strategies. Chin. Hosp. Manag. 2019, 39, 65-67, 74.

23. Wang, Z.J.; Zhang, P.W.; Liu, M.C.; Yang, Z.R.; Pei, C.Y.; Sun, J.; Liu, Y.L. Outpatient experiences: Major findings from the third-party evaluation of the China Healthcare Improvement Initiative. J. Chin. Res. Hosp. 2020, 7, 51-56, 167-173.

24. Yu, H.; Pan, H.W.; Zhang, X. The Analysis on the Agents of Doctor-patient Culture Conflicts in Clinical Diagnosis and Treatment. Med. Philos. B 2015, 36, 88-90.

25. Bai, N.; Yin, M. Interpretation of the Doctor-patient Conflict in China from the Perspective of Social Culture Comparison between China and Western. Med. Philos. A 2012, 33, 36-38.

26. The Work Bank; World Health Organization; Ministry of Finance of the People's Republic of China; National Health Commission of the People's Republic of China; Ministry of Human Resources and Social Security of the People's Republic of China. Deepening Health Reform in China: Building High-Quality and Value-Based Service Delivery. 2016. Available online: http:/ / documents1.worldbank.org/curated/zh/707951469159439021/pdf/107176-REVISED-PUBLIC-CHINESE-HealthReform-In-China-Policy-Summary-Oct-reprint-CHN.pdf (accessed on 14 March 2021). 
27. Tucker, J.D.; Cheng, Y.; Wong, B.; Gong, N.; Nie, J.; Zhu, W.; McLaughlin, M.M.; Xie, R.; Deng, Y.; Huang, M.; et al. Patientphysician mistrust and violence against physicians in Guangdong Province, China: A qualitative study. BMJ Open 2015, 5, e8221. [CrossRef] [PubMed]

28. Xia, Y.; Zeng, X.; Wang, Z. Recognition of relationship between doctors and patients among medical staff. Chin. J. Public Health 2013, 29, 1638-1641.

29. Mo, X.; Xu, L.; Luo, H.; Gai, R. Medical Professional Perceived Doctor-patient Relationship, Job Satisfaction and Turnover Intention. Chin. J. Clin. Psychol. 2015, 23, 141-146.

30. Sun, J.; Zhang, L.; Mu, P.; Wan, Y.; Liu, J.; He, C. Differences in the cognitive evaluation of the doctor-patient relationship between the medical side and the contracting parties. Chin. Ment. Health J. 2016, 30, 486-491.

31. WW, L.; HL, W. Assessment of Patient-Doctor Depth-of-Relationship Scale and Influencing Factors for the Depth of Patient-doctor Relationship. Chin. Gen. Pract. 2015, 22, 2705-2708.

32. Ma, T.; Li, J.; Wang, J.; Zhang, L.; Chen, H. Relationship Among Perceived Physician—Patient Relationship, Job Involvement and Job Satisfaction of Medical Staffs in Jinli Province. Med. Soc. 2018, 31, $62-65$.

33. Zhang, X.; Liu, Y.; Tu, L.; Hu, Y. The Overall Evaluation of the Current Tense Doctor-patient Relationship in China. Mod. Hosp. Manag. 2014, 12, 6-10.

34. Dickinson, G.E.; Pearson, A.A. Sex-Differences of Physicians in Relation to Dying Patients. J. Am. Med. Womens Assoc. 1979, 34, 45-47.

35. Yang, H.; Lu, M.; He, L. A comparison and analysis of the present status of doctor-Patient relationship among medical staffs and patients: A meta-analysis. J. Xiangnan Univ. (Med. Sci.) 2015, 17, 7-10.

36. Gray, J. The effect of the doctor's sex on the doctor-patient relationship. J. R. Coll. Gen. Pract. 1982, 236, 167-169.

37. Walton, H.J. Sex differences in ability and outlook of senior medical students. Br. J. Med. Educ. 1968, 2, 156-162. [CrossRef] [PubMed]

38. Davis, M.S.; Cartwright, A. Patients and Their Doctors: A Study of General Practice. Am. Soc. Rev. 1968, 33, 997. [CrossRef]

39. Abiola, T.; Udofia, O.; Abdullahi, A. Patient-doctor relationship: The practice orientation of doctors in Kano. Niger. J. Clin. Pract. 2014, 17, 241. [CrossRef]

40. Babitsch, B.; Braun, T.; Borde, T.; David, M. Doctor's perception of doctor-patient relationships in emergency departments: What roles do gender and ethnicity play? BMC Health Serv. Res. 2008, 8, 82. [CrossRef]

41. Wang, G.; Xu, Y.; Wang, W.; Liu, Q.; Zhao, Y.; Jiang, S.; Luo, J. Differences and Influencing Factors in the Evaluation of the Doctor-patient Relationship between the Medical Side and the Contracting Parties. Chin. J. Soc. Med. 2018, 35, 522-526.

42. Xing, K.; Zhang, X.; Jiao, M.; Cui, Y.; Lu, Y.; Liu, J.; Zhang, J.; Zhao, Y.; Zhao, Y.; Li, Y.; et al. Concern about Workplace Violence and Its Risk Factors in Chinese Township Hospitals: A Cross-Sectional Study. Int. J. Environ. Res. Public Health 2016, $13,811$. [CrossRef] [PubMed]

43. Roseanne Moody, F.; Marcee, E.; Lisa, B.; Renee, B.; Linda, W.; Marilyn, S.; Louise, A. A qualitative study of continuing education needs of rural nursing unit staff: The nurse administrator's perspective. Nurs. Educ. Today 2013, 33, 364-369.

44. Zhang, P.; Wang, F.; Cheng, Y.; Zhang, L.Y.; Ye, B.Z.; Jiang, H.W.; Sun, Y.; Zhu, X.; Liang, Y. Impact of organizational and individual factors on patient-provider relationships: A national survey of doctors, nurses and patients in China. PLoS ONE 2017, 12, e181396. [CrossRef] [PubMed]

45. Qiao, T.; Fan, Y.; Geater, A.F.; Chongsuvivatwong, V.; McNeil, E.B. Factors associated with the doctor-patient relationship: Doctor and patient perspectives in hospital outpatient clinics of Inner Mongolia Autonomous Region, China. Patient Prefer. Adherence 2019, 13, 1125-1143. [CrossRef]

46. Yu, Y.; Hao, Y.; Liang, L.; Wu, Q.; Zhang, Y.; Kang, Z.; Jiao, M.; Pan, Q. Analysis of medical staff perspective factors influencing a harmonious doctor-patient relationship: Based on 27 public hospitals of Heilongjiang province. Chin. J. Health Policy 2016, 9 , 15-19.

47. Zeng, Y.; Zhang, L.; Yao, G.; Fang, Y. Analysis of current situation and influencing factor of medical disputes among different levels of medical institutions based on the game theory in Xiamen of China: A cross-sectional survey. Medicine (Baltimore) 2018, 97, e12501. [CrossRef] [PubMed]

48. Hahn, S.; Zeller, A.; Needham, I.; Kok, G.; Dassen, T.; Halfens, R.J.G. Patient and visitor violence in general hospitals: A systematic review of the literature. Aggress. Violent Behav. 2008, 13, 431-441. [CrossRef]

49. Olsen, D.; Bellass, S.; Stievano, A.; Johnson, M.; Rocco, G.; Sabatino, L. Nursing's professional respect as experienced by hospital and community nurses. Nurs. Ethics 2018, 25, 665-683.

50. He, A.J.; Qian, J. Explaining Medical Disputes in Chinese Public Hospitals: The Doctor-Patient Relationship and Its Implications for Health Policy Reforms. Health Econ. Policy Law 2016, 11, 359-378. [CrossRef]

51. Yang, Q.; Zhang, H.; Yu, M.; Hu, X.; Gu, Y.; Sun, X.; Zhen, X.; Gu, S.; Huang, M.; Wei, J.; et al. Chinese Minority Perceives the Doctor-Patient Relationship Differently: A Cultural and Economic Interpretation. Front. Public Health 2019, 7, 330. [CrossRef]

52. Zhang, J.; Teng, W.; Tang, M.; Zhu, J.; Cai, W. Comparison Study on Cognition of Doctor-patient Relationship between Doctors and Patients. Med. Philos. 2012, 33, 58-59.

53. Zhang, J.; Teng, W.; Tang, M.; Zhu, J.; Cai, W. Influencial Factors Analysis and Policy Selection of Physician-Patient Relationship in View of Hospital and Medical staff. Chin. Med. Ethics 2011, 24, 123-125. 
54. Namazi, H.; Aramesh, K.; Larijani, B. The doctor-patient relationship: Toward a conceptual re-examination. J. Med Ethics Hist. Med. 2016, 9, 10.

55. Benatar, S.R. The changing doctor-patient relationship and the new medical ethics. SA J. Contin. Med. Educ. 1987, 5, 32-34.

56. Beraldi, A.; Kukk, E.; Heußner, P.; Herschbach, P. Bedarf, Kenntnis, Akzeptanz und Nutzung von psychosozialen Angeboten. Onkologe 2016, 22, 121-126. [CrossRef]

57. Hahn, S.R.; Thompson, K.S.; Wills, T.A.; Stern, V.; Budner, N.S. The difficult doctor-patient relationship: Somatization, personality and psychopathology. J. Clin. Epidemiol. 1994, 47, 647-657. [CrossRef]

58. Gulbrandsen, P.; Hjortdahl, P.; Fugelli, P. General practitioners' knowledge of their patients' psychosocial problems: Multipractice questionnaire survey. BMJ 1997, 314, 1014-1018. [CrossRef]

59. Wu, W.; Xu, J.; Wang, Y.; Ni, J.; Liu, D.; Zhou, B. Analyzing the influence of medical expenditure on doctor-patient relationship. Chin. Health Serv. Manag. 2013, 5, 332-333, 355.

60. Skirbekk, H.; Middelthon, A.; Hjortdahl, P.; Finset, A. Mandates of Trust in the Doctor-Patient Relationship. Qual. Health Res. 2011, 21, 1182-1190. [CrossRef] [PubMed]

61. Dang, B.N.; Westbrook, R.A.; Njue, S.M.; Giordano, T.P. Building trust and rapport early in the new doctor-patient relationship: A longitudinal qualitative study. BMC Med. Educ. 2017, 17, 32. [CrossRef]

62. Weber, A.S.; Verjee, M.A.; Musson, D.; Iqbal, N.A.; Mosleh, T.M.; Zainel, A.A.; Al-Salamy, Y. Patient opinion of the doctor-patient relationship in a public hospital in Qatar. Saudi Med. J. 2011, 32, 293. [CrossRef] [PubMed]

63. Thiels, C.A.; Bergquist, J.R.; Pandian, T.K.; Heller, S.F. Improving Communication Skills and Professionalism Among General Surgery Residents, One Page at a Time. Mayo Clin. Proc. 2016, 91, 539-541. [CrossRef]

64. Liberati, A.; Altman, D.G.; Tetzlaff, J.; Mulrow, C.; Gøtzsche, P.C.; Ioannidis, J.P.A.; Clarke, M.; Devereaux, P.J.; Kleijnen, J.; Moher, D. The PRISMA statement for reporting systematic reviews and meta-analyses of studies that evaluate healthcare interventions: Explanation and elaboration. BMJ 2009, 339, b2700. [CrossRef] [PubMed]

65. Group GW. Grading of Recommendations Assessment, Development and Evaluation. 2011. Available online: https://www. gradeworkinggroup.org/ (accessed on 25 March 2021).

66. Higgins, J.P.; Thompson, S.G.; Deeks, J.J.; Altman, D.G. Measuring inconsistency in meta-analyses. BMJ 2003, 327, 557-560. [CrossRef]

67. Shi, L.; Zhang, D.; Zhou, C.; Yang, L.; Sun, T.; Hao, T.; Peng, X.; Gao, L.; Liu, W.; Mu, Y.; et al. A cross-sectional study on the prevalence and associated risk factors for workplace violence against Chinese nurses. BMJ Open 2017, 7, e013105. [CrossRef]

68. Yuan, T.; Su, T.; Wang, R.; Li, M. Status quo of hospital violence suffered by medical personnel and study on influencing factors. Chin. J. Med. Manag. Sci. 2017, 7, 66-70.

69. Liu, Q.; Wang, Z.; Wu, S.; Sun, J.; Liu, Y. Analysis of influencing factors of medical staffs' perceptions on doctor-patient relationship. Chin. J. Hosp. Adm. 2018, 34, 319-325.

70. Gao, X.; Wang, S.; Jiang, L.; Lu, Y.; Li, P.; Pu, C. Analysis on the Influances of Sanitary Resource Allocation the Doctor-Patient Relationship from the Perspective of Doctors-A Case Study of Chongqing. Chin. Prim. Health Care 2015, 29, 1-4.

71. Zhao, P.; Wang, Z.; Huang, Z.; Liu, S.; Geng, S.; Sun, J.; Liu, Y. Status and Influencing Factor Analysis of the Perception of Outpatients Pertaining to Doctor-patient Relationship. Chin. J. Hosp. Adm. 2018, 34, 123-127.

72. Liu, Y.; Bai, J. The research or current status and causes of medical disputes in part of hospitals in Urumqi. J. Xinjiang Med. Univ. 2010, 33, 554-557.

73. Zhao, W.; Yang, L. Analysis on the Influencing Factors of Doctor-patient Relationship from the Perspective of Medical Staff. Shenzhen J. Integr. Tradit. Chin. West. Med. Jan. 2017, 27, 182-184.

74. Zhang, J.; Teng, W.; Tang, M.; Zhu, J.; Cai, W. Influencial Factors Analysis and Policy Discussion of Physician-Patient Relationship in View of Patients' Side. Chin. Med. Ethics 2011, 24, 199-200.

75. Yang, J.; Zhang, X.; Chen, J. Basic Cognition on Doctor-patient Relationship Influencing Factors in Patients of Pilot Reform Hospital at Country Level. Chin. Med. Ethics 2014, 27, 92-95.

76. Deng, F. The current situation and influencing factors of doctor-patient relationship in a hospital in Changsha. Pract. Prev. Med. 2010, 17, 182-183.

77. Wang, Z.; Meng, X. A Study on the Influencing Factors of Medical Disputes in a City's 3A Grade Hospitals. J. Math. Med. 2015, 28, 515-517.

78. Yin, X.Y. Two Misunderstandings in Cognition of Doctor-Patient Relationship and Ethical Analysis. Hosp. Manag. Forum 2005, 2, 37-39.

79. Zhou, L.; Xu, Z.Q. A comparative study on the cognition of doctors and patients on doctor-patient relationship based on investigation in Jinhua area. Chin. Nurs. Res. 2017, 31, 1013-1016.

80. Lei, Y.; Wu, M. Survey on Medical Staffs' Perception of Doctor-Patient Relationship: A Case Study of A Public Hospital in Beijing. Pract. J. Card. Cereb. Pneumal Vasc. Dis. 2010, 18, 1055-1057.

81. Zhu, L.; Liu, K.; Bai, G.; Yuan, M.; Yi, D. Cognitive Differences of Doctor-patient Relationship between Doctors and Patients in Xilinhot Lnner Mongolia. Mil. Med. J. South China 2012, 26, 258-261.

82. Yu, C.L.; Chen, Y.X.; Li, J.; Fan, X.W. Evaluation and Investigation on Job Satisfaction of Medical Staff in Public Hospital of Jiangsu Province. Med. Philos. 2020, 41, 40-43.

83. Sun, L.R.; Yang, Z.L. The Effect of Social Prejudice and Group Threat on the Intergroup Conflict. J. Psychol. Sci. 2013, 36, 949-955. 
84. HE, J.A. Why Do Chinese Physicians Over-Prescribe?: Evidence from a Survey in Shenzhen, China The Doctor-Patient Relationship, Defensive Medicine and Overprescription in Chinese Public Hospitals: Evidence from a Cross-Sectional Survey in Shenzhen City. 2014. Available online: https://repository.eduhk.hk/en/publications/why-do-chinese-physicians-overprescribeevidence-from-a-survey-in-3 (accessed on 23 March 2021).

85. Baker, H. Doctor-Patient Relationship or Doctor-Public Relationship. Can. Med. Assoc. J. 1958, 78, 128-131.

86. Wang, H.X. To Change the Current Situation of the Expansion of Large Hospitals Should Not Be Blocked. Chin. Health Insur. 2015, $5,26-27$.

87. Zhang, W. Set up "People-Oriented" thought to Respect the Medical Service Needs of Patients. Jiangsu Health Syst. Manag. 2005, $1,27$.

88. Lv, G.; Ji, Y.; Yuan, K.H.; Liu, T.F. Analysis on the status quo, dilemma and countermeasures of tiered medical system. Chin. Hosp. 2020, 24, 4-7.

89. Shen, S.L.; Yu, X.S. Enlightenment of the UK Essential Healthcare System and Its Reform to General Practice Development in China. Chin. Gen. Pract. 2019, 22, 2286-2292.

90. James, W.C. The patient/physician relationship: One doctor's view. Health Aff. 1995, 14, 209.

91. Robinson, G. Effective doctor patient communication: Building bridges and bridging barriers. Can. J. Neurol. Sci. 2002, 29 (Suppl. 2), S30. [CrossRef]

92. Cartwright, L.K. Personality differences in male and female medical students. Psychiatry Med. 1972, 3, 213-218. [CrossRef] [PubMed]

93. Xu, Y.; Li, J. Current Situation of Humanistic Care Ability of Medical Staff under the Background of Medical Education Cooperation. Guide Sci. Educ. 2020, 10, 184-185.

94. Xu, H.; Zhang, Q.J. Investigation on Medical Humanistic Literacy of the Eight-Year Program Cadets in Military Medical Hospital. Med. Philos. 2020, 41, 66-69.

95. Ying, M.Z.; Wang, Y.J. Medical Humanity and Doctor-Patient Relationship. Med. Educ. Res. Pract. 2014, 22, 1086-1088.

96. He, X.S. The influence of humanistic care education of medical students on future doctor-patient relationship. China Extracurric. Educ. 2015, z1, 697.

97. Loh, K.Y.; Sivalingam, N. Enhancing doctor-patient relationship: The humanistic approach. Med. J. Malays. $2008,63,85-87$.

98. Alcorta-Garza, A.; González-Guerrero, J.F.; Tavitas-Herrera, S.E.; Rodríguez-Lara, F.J.; Hojat, M. Validity and reliability of the Jefferson Scale of Physician Empathy in Mexican medial students. Salud Ment. 2005, 28, 57-63.

99. Yang, Y.; Liu, Y.; Zhang, H.; Liu, J.; Liu, H.; Liu, H. Prevalence and influence factors of workplace violence among nurses in 3A grade hospitals. Chin. J. Public Health 2015, 31, 1155-1159.

100. Loffler, C.; Hock, J.; Hornung, A.; Kundt, G.; Drewelow, E.; Volker, S.; Kreiser, B.; Riedel, J.; Altiner, A. What Makes Happy Doctors? Job Satisfaction of General Practitioners in Mecklenburg-Western Pomerania-A Representative Cross-sectional Study. Gesundheitswesen 2015, 77, 927-931.

101. Daghio, M.M.; Ciardullo, A.V.; Cadioli, T.; Delvecchio, C.; Menna, A.; Voci, C.; Guidetti, P.; Magrini, N.; Liberati, A. GPs' satisfaction with the doctor-patient encounter: Findings from a community-based survey. Fam. Pract. 2003, 20, 283-288. [CrossRef]

102. Archibald, C. Job satisfaction among neonatal nurses. Pediatric Nurs. 2006, 32, 176-179, 162.

103. Wu, D.; Wang, Y.; Lam, K.F.; Hesketh, T. Health system reforms, violence against doctors and job satisfaction in the medical profession: A cross-sectional survey in Zhejiang Province, Eastern China. BMJ Open 2014, 4, e6431. [CrossRef]

104. Lu, Y.; Hu, X.; Huang, X.; Zhuang, X.; Guo, P.; Feng, L.; Hu, W.; Chen, L.; Hao, Y. Job satisfaction and associated factors among healthcare staff: A cross-sectional study in Guangdong Province, China. BMJ Open 2016, 6, e11388. [CrossRef]

105. Zhang, X.; Sleeboom-Faulkner, M. Tensions between medical professionals and patients in mainland China. Camb. Q. Healthc. Ethics 2011, 20, 458-465. [CrossRef]

106. Han, R.; Wei, L.; Li, J.; Zhang, D.; Li, H. The Mediating Effects of Job Satisfaction on the Association between Doctor-patient Relationship and OCB among Physicians in China. Iran. J. Public Health 2018, 47, 698-705. [PubMed]

107. Zhang, Y.; Feng, X. Empirical study on determinants of physicians' job satisfaction in urban public medical institutions. Chin. Health Resour. 2011, 14, 77-79.

108. Liebman, B.L. Malpractice mobs: Medical dispute resolution in China. Columbia Law Rev. 2013, 113, 181-264.

109. Wang, L.; Wu, Q.; Shan, L.; Parasor, A.; Li, Y.; Kang, Z.; Hao, J.; Pan, Q.; Liang, Z. Key Dimension Analysis of the Impact of Health Insurance on Doctor-patient Relationship: A Comparative Study Between China and Canada. Chin. Hosp. Manag. 2017, 37, 40-43.

110. Chin, J.J. Doctor-patient relationship: A covenant of trust. Singap. Med. J. 2001, 42, 579.

111. Eveleigh, R.M.; Muskens, E.; van Ravesteijn, H.; van Dijk, I.; van Rijswijk, E.; Lucassen, P. An overview of 19 instruments assessing the doctor-patient relationship: Different models or concepts are used. J. Clin. Epidemiol. 2012, 65, 10-15. [CrossRef] [PubMed]

112. Bending, Z.J. Reconceptualising the Doctor-Patient Relationship: Recognising the Role of Trust in Contemporary Health Care. J. Bioethical Inq. 2015, 12, 189-202. [CrossRef] [PubMed]

113. Lin, X.; Wang, M.; Zuo, Y.; Li, M.; Lin, X.; Zhu, S.; Zheng, Y.; Yu, M.; Lamoureux, E.L. Health literacy, computer skills and quality of patient-physician communication in Chinese patients with cataract. PLoS ONE 2014, 9, e107615. [CrossRef]

114. Wallis, W. Communication as fundamental to the Doctor-Patient relationship. Acta Biomed. Ateneo Parm. $2008,79,52$. 
115. Singh, M. Communication as a Bridge to Build a Sound Doctor-Patient/Parent Relationship. Indian J. Pediatrics 2016, 83, 33-37. [CrossRef] [PubMed]

116. Brown, P.R. Trusting in the New NHS: Instrumental versus communicative action. Soc. Health Illn. 2008, 30, 349-363. [CrossRef]

117. Truog, R.D. Patients and doctors-evolution of a relationship. N. Engl. J. Med. 2012, 366, 581-585. [CrossRef] [PubMed]

118. Kharde, A.P.R.P.J. Dynamics of Doctor-Patient Relationship: A Cross-Sectional Study on Communication and Patient Satisfaction. Int. J. Health Sci. Res. 2016, 2, 65-68.

119. Zolnierek, K.B.; Dimatteo, M.R. Physician communication and patient adherence to treatment: A meta-analysis. Med. Care 2009, 47, 826-834. [CrossRef]

120. Duan, G.; Qiu, L.; Yu, W.; Hu, H. Outpatient service quality and doctor-patient relationship: A study in Chinese public hospital. Int. J. Serv. Econ. Manag. 2014, 6, 97. [CrossRef]

121. Guimin, D.; Weiping, Y.; Jiawei, L.; Hongmei, Y. The research of factors influence doctor-patient relationship quality: Investigation of public hospitals in Sichuan province. In Proceedings of the 2016 13th International Conference on Service Systems and Service Management (ICSSSM), Kunming, China, 24-26 June 2016; pp. 1-6.

122. Pan, Q.; Liang, L.; Wu, Q.; Hao, J.; Tao, S.; Huang, Z.; Shi, W.; Sun, H.; Jiao, M.; Yu, Y.; et al. Analysis of Factors Influencing the Doctor-patient Relationship: A Perspective Based on the Doctors and Patients in Public Hospitals. Chin. Hosp. Manag. 2016, 36, 68-70.

123. Chen, Q.; Zheng, H. Review of Research on Doctor-patient Relationship at Home and Abroad. Med. Philos. 2014, 35, 44-48.

124. Zhu, L.; Yuan, Y. The types, characteristics and countermeasures of doctor-patient contradictions in China at present. Soc. Sci. Res. 2014, 6, 104-111.

125. Sun, H.; Liu, Y. To solve the dilemma of "difficult to see a doctor and expensive to see a doctor" by tiered diagnosis and treatment: From the perspective of supply and demand. Theor. Explor. 2017, 4, 93-98. 